\title{
Study on Downhole Throttling Characteristics of High Water Content Gas
}

\author{
Jie Zheng, ${ }^{1,2,3,4}$ Zhenzhen Li ${ }^{1,2}$ Yihua Dou, ${ }^{1,2}$ Yarong Zhang, ${ }^{5}$ Cheng $\mathrm{Bi}^{3}{ }^{3}$ Xu Yang, ${ }^{3}$ \\ and Jiahui $\mathrm{Li}^{1,2}$ \\ ${ }^{1}$ School of Mechanical Engineering, Xi'an Shiyou University, Xi'an, Shaanxi 710065, China \\ ${ }^{2} X i$ 'an Key Laboratory of Wellbore Integrity Evaluation, Xi'an, Shaanxi 710055, China \\ ${ }^{3} X i$ 'an Special Equipment Inspection Institute, Xi'an, Shaanxi 710065, China \\ ${ }^{4}$ School of Power and Energy, Northwestern Polytechnical University, Xi'an, Shaanxi 710072, China \\ ${ }^{5}$ School of Science, Xi'an University of Architecture and Technology, Xi'an, Shaanxi 710055, China
}

Correspondence should be addressed to Zhenzhen Li; lizhenzhen1997@126.com

Received 7 October 2021; Revised 6 December 2021; Accepted 22 December 2021; Published 24 January 2022

Academic Editor: Steffen Berg

Copyright (C) 2022 Jie Zheng et al. This is an open access article distributed under the Creative Commons Attribution License, which permits unrestricted use, distribution, and reproduction in any medium, provided the original work is properly cited.

In order not to hinder gas production, we usually hope that the bottom hole effusion can be discharged to the surface with highpressure natural gas. For the production data of high water content gas wells, the problems of insufficient water content and liquid-carrying capacity affecting gas well production should be considered. Based on the wellbore gas-liquid two-phase pipe flow theory and heat transfer theory, the temperature and pressure coupling prediction model of a high water-bearing gas well is established. Combined with the downhole throttling mechanism and gas-liquid two-phase homogeneous flow theory, the temperature and pressure field distribution model is established. The results show that compared with the Ramey model and Hassan and Kabir model, the temperature and pressure coupling prediction model of high water-bearing gas wells established in this study has the smallest coefficient of variation in the four groups of data tests. Based on this, the effects of different working conditions and choke diameter on downhole throttling characteristics of high water-bearing gas wells are analyzed. The findings of this study are helpful to better predict the wellbore temperature and pressure coupling of high water-bearing gas wells and provide more effective help for the smooth production of gas wells.

\section{Research Status of Gas-Liquid Two- Phase Well}

The prediction of wellbore temperature and pressure field has always been a major problem of common concern to scientists [1] because it is related to the accurate construction of oil production technology $[2,3]$, the safety of pipe string [4-6], the normal use of various downhole tools [7], the reliability of production process [8], and the wax and scale prevention of oil and gas wells affected by temperature and pressure [9-12]. Nowadays, in the daily production process of gas wells, the phase change of natural gas in the wellbore is becoming more and more common $[13,14]$. For example, affected by the formation and other environmental factors, formation water or other free water often appears in the wellbore of producing gas wells, and a large amount of accumulation will lead to fluid accumulation in the wellbore. The site often hopes that the water infiltrating from the formation to the bottom of the well can be carried to the ground by high-pressure natural gas fluid in time. In order to solve this engineering problem, many scholars have proposed new calculation methods to calculate and obtain the relevant data of gas well temperature, pressure field, and liquid carrying.

Abdelhafiz et al. [15] proposed a model for predicting the temperature distribution of vertical wellbore systems under circulation and shut-in conditions. The model can simulate the transient temperature disturbance of drilling fluid, drill string, casing string, cement behind the casing, and surrounding rock formation. However, the coupling 
effect of temperature and pressure is not considered in the model. Turner first considered the wellbore flow process and established the droplet model. Among them, the calculation formula of critical gas velocity and the droplet parameters carried by gas flow are obtained based on the droplet geometric size and force model [16]. However, the model has requirements for the gas-liquid ratio. When the gasliquid ratio reaches a specific value $\left(\mathrm{GLR}>1400 \mathrm{~m}^{3} / \mathrm{m}^{3}\right)$, the model can be applied to the gas well with annular fog flow. Based on Turner's model, Gray considered the influence of temperature gradient, gas composition, fluid acceleration, and other factors during liquid carrying in gas wells and obtained the wellbore pressure drop of gas-liquid twophase pipe flow by using an empirical model [17]. However, the Gray model has no different flow patterns, which is only applicable to stable wellbore flow and not applicable to production wells with effusion. In 2006, Ghalambor and Xu proposed a new liquid-carrying model for gas wells [18]. In view of the difficulty in calculating the pressure of multiphase flow gas wells, a simplified process is adopted. It is considered that the kinetic energy of the gas is only slightly higher than that required for liquid carrying in order to bring droplets from the bottom of the well to the surface. A method to predict critical flow is used to solve the defects of the Turner model, which cannot effectively calculate the pressure of multiphase flow gas wells, but the model only explains the droplet being brought out of the wellhead from the macro perspective, without considering the effects of droplet morphology and wellbore environment. Based on the formation process of droplets in gas wells, Li et al. proposed an ellipsoidal droplet model considering factors such as pressure and environment [19]. The calculation method of liquid-carrying critical flow is obtained. Compared with the Turner model, the calculated value is about $38 \%$ of its result, which is more accurate than the Turner model, but the model does not take into account the influence of wellbore pressure and temperature environment on liquidcarrying capacity. In 2010, Chaoyang adopted a new ellipsoid model [20], considered the influence of droplet physical model and size on stress mode, analyzed the liquid-carrying process of gas wells with liquid in the wellbore, and obtained a new ellipsoid calculation model. However, the application is limited by the field well conditions.

In 2012, Zhibin and Yingchuan considered the influence of droplet parameters, stress model, and other factors on the liquid-carrying capacity and gave a reasonable explanation for the difference in the calculation results of liquidcarrying capacity of each gas field [21], but the model ignored the change of fluid flow pattern in the wellbore. In 2012, Zhi et al. established the critical liquid-carrying model in the throttling process. It is qualitatively analyzed that downhole throttling can improve the liquid-carrying capacity of gas wells [22], but the model fails to solve the quantitative relationship between liquid-carrying flow and gas production. In 2014, Gang simplified the calculation of droplet surface tension, ignored the influence of surface tension on the critical flow of liquid carrying, and replaced it with quantitative constant. It is considered that the surface tension will change with different temperatures and pressure
[23], but the quantitative relationship between surface tension and temperature and pressure is not described. In 2018, aiming at the problem of insufficient liquid-carrying capacity of low-pressure and low-yield gas wells, Yang calculated the changes of critical liquid-carrying flow at different depths [24] and obtained that high-pressure gas wells mostly occurred at the wellhead and low-pressure and low-yield gas wells mostly occurred at the bottom of the well. However, he did not establish an appropriate critical liquid-carrying flow prediction model but made a qualitative judgment. In 2020, Jinbao established the prediction model of critical liquidcarrying velocity of inclined gas wells based on the characteristics of gas-liquid two-phase flow [25] and carried out multiparameter sensitivity analysis. The prediction effect of the model based on an annular fog flow pattern is better.

Through the above data investigation, it is concluded that considering the throttling process, there is little research on the change of critical liquid carrying the flow of gas well, and the research on the change of flow pattern in wellbore on the change of critical liquid carrying the flow of gas well is rarely involved. Therefore, it is necessary to study the simulation of two-phase throttling temperature and pressure field in high water-bearing gas wells. In addition, the above methods do not mention the prediction of wellbore temperature and pressure of high water cut natural gas under high temperature and high pressure. Therefore, taking the gas wells in the Daning Jixian block as the research object, this paper not only considers the wellbore heat transfer but also considers the influence of formation temperature and wellbore pressure on the phase state of natural gas, establishing the wellbore pressure coupling model of water-bearing gas wells, and discusses the tubing diameter, gas production, and the relationship between gas water ratio and wellbore temperature field and pressure field. The technical process of this study is shown in Figure 1.

Firstly, the gas-liquid two-phase pipe flow model of a high water-bearing gas well is given. Secondly, the gas well temperature and pressure are calculated according to the model, and the relative errors are compared with the Ramey model, Hassan and Kabir model, and field measured data. Then, the downhole throttling model of high water content gas well is introduced to calculate the throttling pressure and temperature drop of high water content gas well, and an example of gas well throttling pressure and temperature drop is analyzed. Finally, the numerical simulation of downhole throttling is carried out.

\section{Temperature Pressure Coupling Calculation of High Water-Bearing Gas Well}

Based on the wellbore heat transfer mechanism, considering the gas thermophysical parameters and Joule Thomson coefficient, a wellbore pressure-temperature coupling prediction model for high water-bearing gas wells is established. The relationship between the prediction model and Hassan and Kabir model, Ramey model, and field measured data is explored by using the coefficient of variation method, the accuracy of the model is verified, the sensitivity of wellbore temperature and pressure field is analyzed, and the 


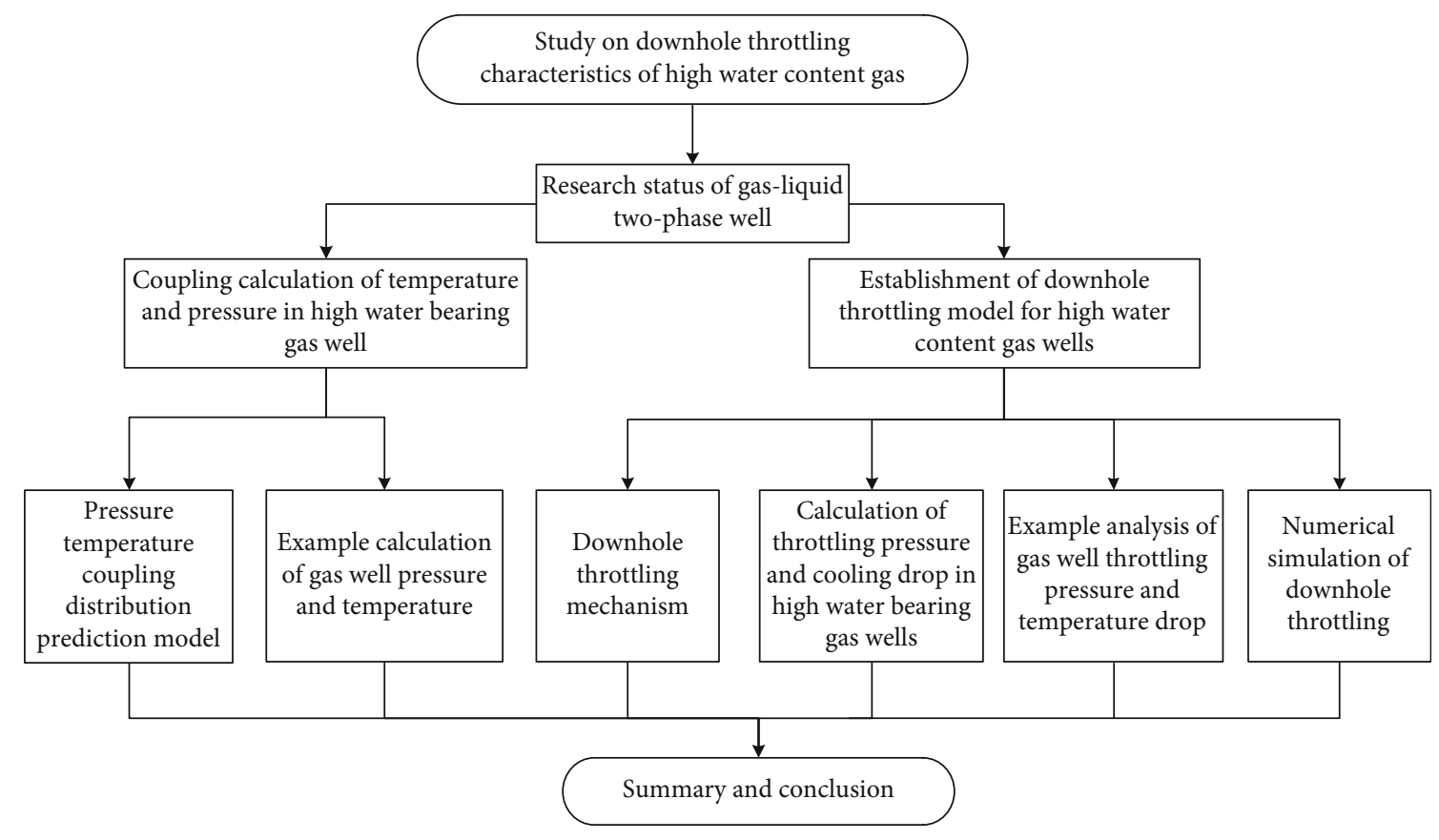

FIgUre 1: Technical flowchart.

relationship between tubing inner diameter, gas production, and gas water ratio and wellbore temperature and pressure field of high water cut gas wells is explored. The wellbore temperature and pressure coupling model of single-phase gas well and the temperature and pressure calculation model of high water-bearing gas well are established, respectively. The models are verified by Daji 14-1 and Daji 4-5 gas wells.

\subsection{Prediction Model of Wellbore Pressure Temperature} Coupling Distribution in High Water-Bearing Gas Wells. Gas wells with low liquid content are generally treated as single-phase pure gas wells, but for gas wells with high water content, the pressure and temperature prediction model of single-phase gas wells cannot meet the accuracy requirements, so it is necessary to reestablish the pressure and temperature prediction model on the basis of considering water content.

In the daily production and management of natural gas wells, the gas phase plays a dominant role, and there is only a small amount of liquid. However, with the continuous extension of production time, the liquid content in the wellbore will also increase so that the flow characteristics in the whole wellbore are completely different from the flow of pure gas, reflecting the characteristics of two-phase flow. In addition, due to the continuous attenuation of temperature and pressure in the wellbore from the bottom to the ground, mass exchange between gas and liquid occurs, and the physical parameters of gas and liquid change at the same time. Therefore, it is necessary to establish a gas-liquid twophase pipe flow model in high water-bearing gas wells to describe the dynamic model of gas and liquid wellbore flow.

The fluid flow in the wellbore is regarded as onedimensional flow, that is, the flow parameters and physical parameters of gas and liquid phases on any section of the pipeline are uniform, which is the average value of the section. The homogeneous flow model in the two-phase flow research method is used for analysis.

2.1.1. Continuity Equation. Take the one-dimensional micro element section $d z$ to study; its diameter is $d$ and the pipe cross-sectional area is $A$, as shown in Figure 2. Establish the flow model along the flow direction, and the continuity equation can be expressed as

$$
\rho_{g} u_{g} a+\rho_{l} u_{l}(1-a)=\frac{Q}{A}=G \text {. }
$$

Known

$$
\rho_{m}=a \rho_{g}+(1-a) \rho_{l}
$$

In the homogeneous flow model, the sliding velocity ratio is 1 , that is, it is considered that there is no sliding between gas and liquid phases, and the volumetric void fraction is equal to the mass void fraction, so the following can be obtained:

$$
\rho_{m}=\beta \rho_{g}+(1-\beta) \rho_{l}
$$

2.1.2. Momentum Equation. Similar to single-phase flow, the momentum equation of homogeneous flow can be expressed in the form of three pressure drop gradients, which can be expressed as

$$
-\frac{d p}{d z}=\left(\frac{d p_{g}}{d z}\right)+\left(\frac{d p_{f}}{d z}\right)+\left(\frac{d p_{a}}{d z}\right)
$$

The pressure gradient generated by the gravity of 


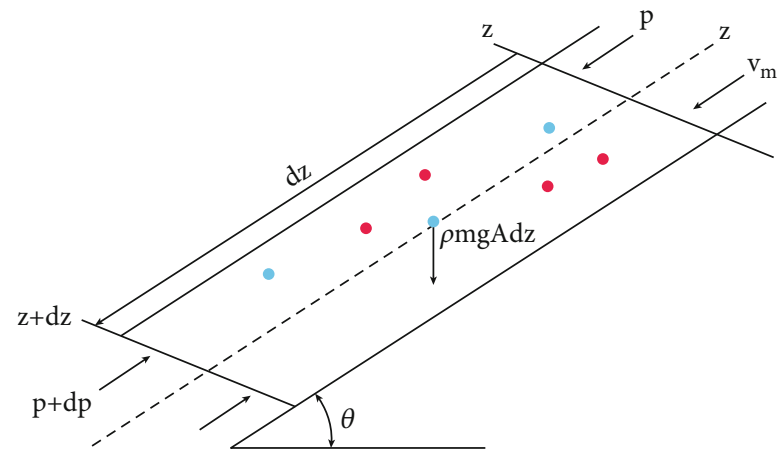

Figure 2: Micro element diagram of one-dimensional gas-liquid two-phase flow.

homogeneous flow is

$$
\left(\frac{d p_{g}}{d z}\right)=\rho_{m} \sin \theta
$$

The friction gradient can be expressed as

$$
\left(\frac{d p_{f}}{d z}\right)=\frac{\tau \pi d}{A}
$$

Sorting:

$$
\left(\frac{d p_{f}}{d z}\right)=2 \rho_{m} g \cdot f \frac{1}{d} \frac{v^{2}}{g}
$$

The acceleration pressure gradient can be expressed as

$$
\left(\frac{d p_{a}}{d z}\right)=G^{2} \frac{d v_{m}}{d z}
$$

Sorting:

$$
-\frac{d p}{d z}=\rho_{m} \sin \theta+2 \rho_{m} g \cdot f \frac{1}{d} \frac{v^{2}}{g}+G^{2}+\frac{d v_{m}}{d z} .
$$

2.1.3. Energy Equation. In the homogeneous flow model, according to the principle of energy conservation, the energy conservation equation of micro element is

$$
\begin{aligned}
& \text { Flow work }+ \text { Internal energy }+ \text { Kinetic energy } \\
& + \text { Potential energy } \\
& \quad=\text { Add heat energy-External work of the system. }
\end{aligned}
$$

It can be expressed as

$$
d(p v)+d U+d\left(\frac{1}{2} u^{2}\right)+g \sin \theta d z=d q-d w
$$

Substitute the basic parameters of two-phase flow:

$$
\begin{aligned}
d\left[a p u_{g}+(1-a) p u_{l}\right] & +d q-p d\left[a u_{g}+(1-a) u_{l}\right] \\
& +d\left[\frac{1}{2} a u_{g}^{2}+\frac{1}{2}(1-a) u_{l}^{2}\right] \\
& +\rho q \sin \theta d z=d q-d w .
\end{aligned}
$$

Because there is no external work during gas-liquid twophase flow in the wellbore, therefore

$$
\begin{aligned}
d\left[a p u_{g}+(1-a) p u_{l}\right] & +d q-p d\left[a u_{g}+(1-a) u_{l}\right] \\
& +d\left[\frac{1}{2} a u_{g}^{2}+\frac{1}{2}(1-a) u_{l}^{2}\right] \\
& +\rho q \sin \theta d z=d q .
\end{aligned}
$$

By introducing the specific enthalpy and taking the micro element section with the length of $d z$ on the oil pipe, the energy conservation equation can be obtained as follows:

$$
\frac{d h}{d z}=-\frac{V_{m} d V_{m}}{d z}-g \sin \theta-\frac{q}{Q}
$$

The specific enthalpy is a function of temperature and pressure, namely,

$$
d h=\left[\frac{\partial h}{\partial T}\right]_{p} d T+\left[\frac{\partial h}{\partial p}\right]_{T} d p=C_{p} d T-C_{J} C_{p} d p
$$

The heat transferred radially to the contact surface between the cement sheath and the formation is expressed as

$$
Q_{1}=-2 \pi r_{\text {to }} U_{\text {to }}\left(T_{f}-T_{s}\right) d z
$$

The radial heat transfer from the cement layer to the surrounding stratum is

$$
Q_{2}=-\frac{2 \pi k_{e}\left(T_{s}-T_{\mathrm{ei}}\right) d z}{f(t)}
$$

The heat transferred to the second contact surface is equal to the heat given to the surrounding formation by the second contact surface. The outlet temperature of each section can be obtained simultaneously:

$$
\begin{aligned}
& T_{\text {fout }}= e^{\lambda\left(z_{\text {out }}-z_{\text {in }}\right)}\left(T_{f \text { in }}-\frac{g \sin \theta}{\lambda C_{p}}+\frac{\eta}{\lambda}-T_{\text {ein }}+\frac{g_{l}}{\lambda}\right) \\
&+\frac{g \sin \theta}{\lambda C_{p}}-\frac{\eta}{\lambda}+T_{\text {eout }}+\frac{g_{l}}{\lambda} \\
& \eta=C_{J} \frac{d p}{d z}-\frac{v}{C_{p}} \frac{d v}{d z}, \lambda=\frac{2 \pi r_{\text {to }} U_{\text {to }} k_{e}}{C_{p} w\left(k_{e}+f(t) r_{\text {to }} U_{\text {to }}\right)} .
\end{aligned}
$$


TABLE 1: Structural parameters of well Daji 14-1 and Daji 4-5.

\begin{tabular}{|c|c|c|c|c|}
\hline & Daji 14-1 well & Daji 4-5 well & Gas water ratio $\left(\mathrm{m}^{3} / \mathrm{m}^{3}\right)$ & 800 \\
\hline Artificial bottom hole (m) & 2448.3 & 2472.3 & Tubing wall thickness $(\mathrm{mm})$ & 6.45 \\
\hline Outer diameter of surface casing $(\mathrm{mm})$ & 244.5 & 244.5 & Formation thermal conductivity $(\mathrm{W} /(\mathrm{m} \cdot \mathrm{K}))$ & 1.72 \\
\hline Wall thickness of surface casing $(\mathrm{mm})$ & 8.94 & 8.94 & Thermal conductivity of oil pipe $(\mathrm{W} /(\mathrm{m} \cdot \mathrm{K}))$ & 50.5 \\
\hline Outer diameter of gas reservoir casing $(\mathrm{mm})$ & 139.7 & 139.7 & Thermal conductivity of casing $(\mathrm{W} /(\mathrm{m} \cdot \mathrm{K}))$ & 50.5 \\
\hline Gas reservoir casing wall thickness $(\mathrm{mm})$ & 9.17 & 9.17 & Thermal conductivity of cement sheath $(\mathrm{W} /(\mathrm{m} \cdot \mathrm{K}))$ & 0.95 \\
\hline Gas production $\left(\mathrm{m}^{3} / \mathrm{d}\right)$ & 30715 & 51220 & Annular thermal convection coefficient $\left(\mathrm{W} /\left(\mathrm{m}^{2} \cdot \mathrm{K}\right)\right)$ & 0.86 \\
\hline Outer diameter of oil pipe $(\mathrm{mm})$ & 88.9 & 88.9 & Fluid convection heat transfer coefficient $\left(\mathrm{W} /\left(\mathrm{m}^{2} \cdot \mathrm{K}\right)\right)$ & 0.82 \\
\hline
\end{tabular}

The Joule Thomson coefficient can be expressed as [26]

$$
C_{J}=\frac{1}{C_{p}}\left[\left(\frac{W_{g} T}{Z_{g} \rho_{g}}\right)\left(\frac{\partial Z_{g}}{\partial Z}\right)_{p}-\frac{\left(1-W_{g}\right)(1-\beta T)}{\rho_{l}}\right],
$$

where $\beta=(1 / v)(\partial V / \partial T)_{p}=(-1 / \rho)(\partial \rho / \partial T)_{p}$.

The wellbore pressure-temperature coupling model of the high water-bearing gas well needs to be solved by an iterative method. The wellbore is divided into $n$ sections. Assuming that the thermophysical parameters in each section are equal, the bottom hole temperature and pressure parameters are set as the boundary conditions, and the relevant physical parameters of the next section are calculated according to the temperature and pressure until the complete wellbore is calculated.

2.2. Example Calculation of Gas Well Pressure and Temperature. Based on the established temperature and pressure coupling model of the high water-bearing gas well, the above model is verified in combination with the field actual wellbore data, and the relative errors between the Ramey model [27], Hassan and Kabir model, temperaturepressure coupling model of high water-bearing gas well, and field measured data are compared. The temperature and pressure distribution of wellbore temperature-pressure field with the change of tubing size, gas production, and gas water ratio is analyzed.

2.2.1. Comparison of Wellbore Temperature and Pressure Field Models. Table 1 shows the wellbore structure parameters of Daji 14-1 and Daji 4-5 in a block.

For the above Daji 14-1 well, the surface casing running depth is $554.91 \mathrm{~m}$, the gas reservoir casing running depth is $2471.75 \mathrm{~m}$, the surface casing running depth of Daji 4-5 well is $554.64 \mathrm{~m}$, and the gas reservoir casing running depth is $2486.47 \mathrm{~m}$. As the overall GWR of the two wells is less than 2000, they cannot be treated as singlephase gas wells. Using the temperature pressure coupling theoretical model of high water-bearing gas wells, write the measured basic parameters of gas wells into the program (such as bottom-hole temperature, bottom hole pressure, well depth, and fluid density in the well) as the initial conditions and replace them into the temperature pressure coupling theoretical model of high water-bearing gas wells set above. The well is divided into micro element segments for an iterative solution. Because the fourth-order Runge Kutta method is more accurate to solve the differential equation, the fourth-order Runge Kutta method is used to solve the differential equation. To sum up, the calculation results through MATLAB programming are shown in Figure 3.

As shown in Figure 3, the wellbore temperature and pressure coupling prediction model of high waterbearing gas well established in this paper has higher accuracy and is closer to the field measured data than the Hassan and Kabir model and Ramey model. It can be seen from the figure that the Ramey model cannot correctly judge the wellbore temperature and pressure field of the high water-bearing gas well; the Hassan and Kabir model is more accurate than the Ramey model because it has the theoretical basis of a two-phase pipe flow model. However, when calculating the wellbore temperature and pressure field, it adopts the method of first calculating the pressure drop and independently considers the relationship between pressure change and temperature change, which has a large deviation from the field reality. For Daji 14-1 well model, the temperature prediction is more accurate and the pressure prediction error is large. There are two reasons for this phenomenon: (1) the model is caused by the discontinuity of formation pressure gradient in pressure calculation; (2) the actual measurement error of the measured pressure data will also lead to the deviation from the theoretical calculation value. For Daji 4-5 well, wellbore pressure prediction is more accurate and temperature error is relatively large. This may be due to the approximate continuous change of geothermal gradient in the calculation of formation temperature. The theoretical model can be applied to engineering practice.

2.2.2. Model Error Analysis. Since the dimensions and well conditions of the four groups of data in Figure 3 are different from each other, a unified error cannot be used for comparative analysis. The coefficient of variation is introduced to describe the deviation between the models relative to the field measured data. The coefficient of variation can be expressed as

$$
C_{v}=\frac{\sigma}{\mu} .
$$



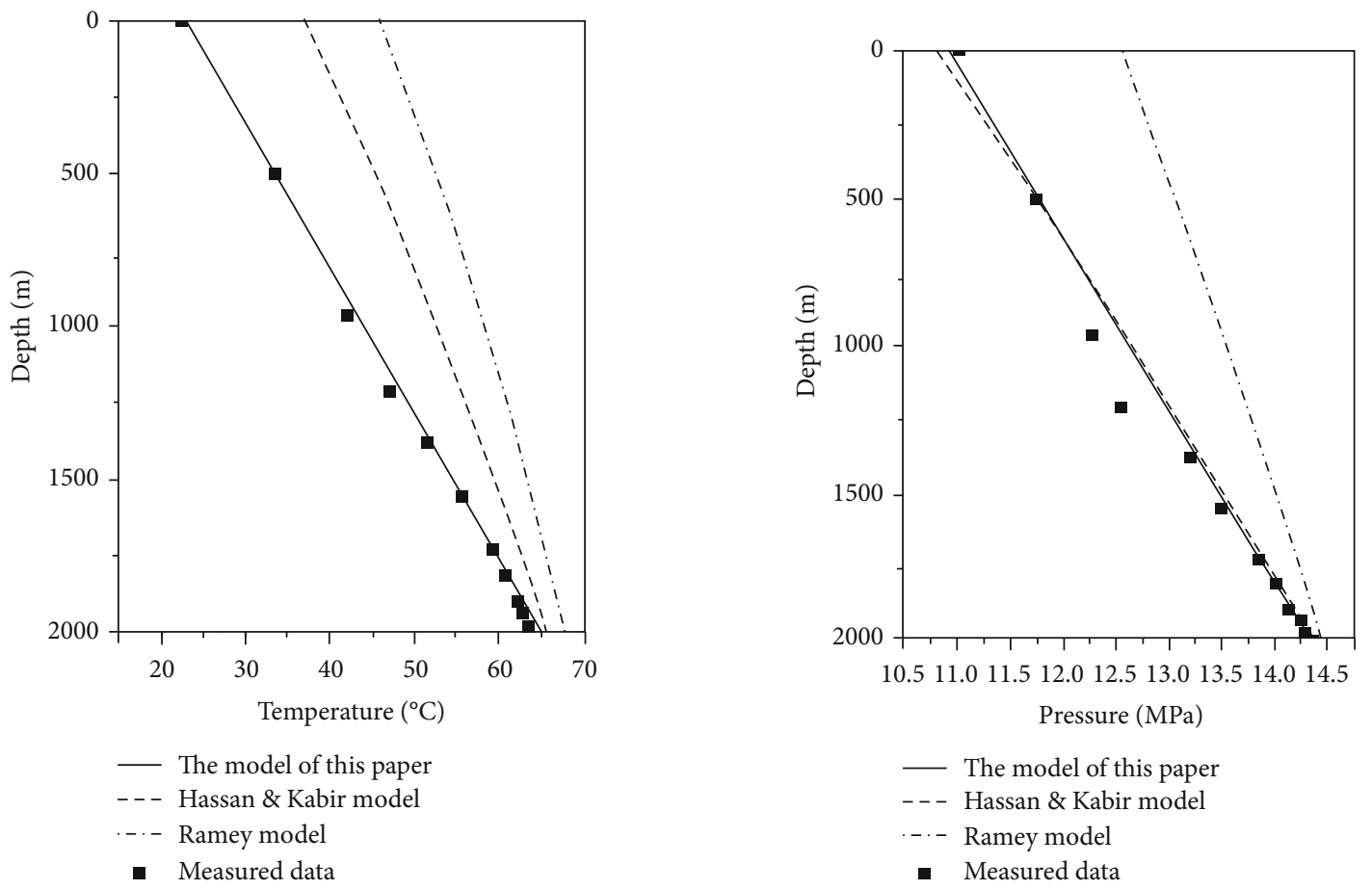

(a) Comparison of wellbore temperature distribution of Daji 14-1 well

(b) Comparison of wellbore pressure distribution of Daji 14-1 well

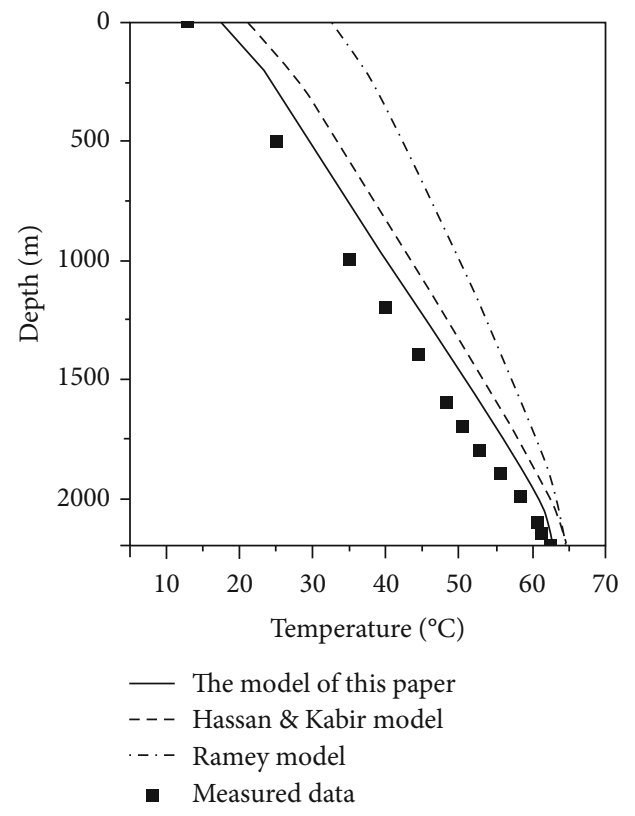

(c) Comparison of wellbore temperature distribution of Daji 4-5 well

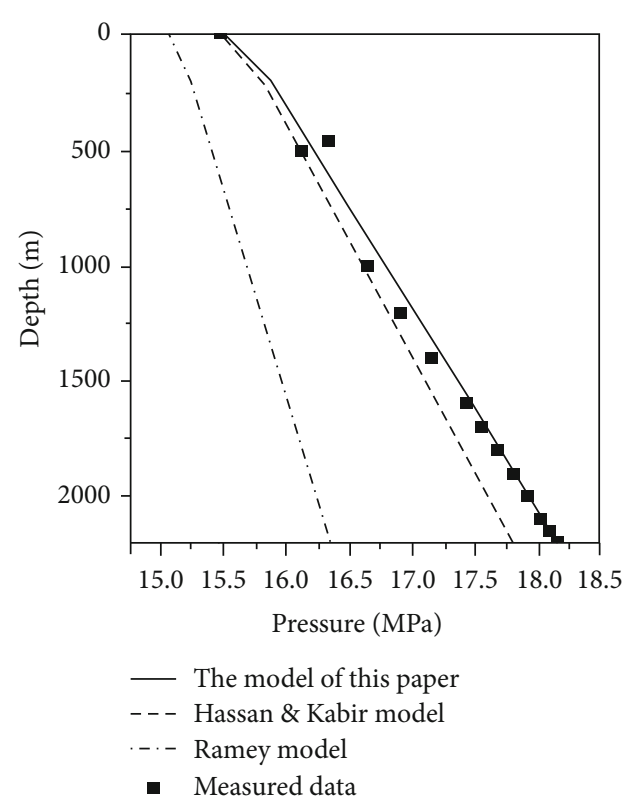

(d) Comparison of wellbore pressure distribution of Daji 4-5 well

FIGURE 3: Wellbore temperature and pressure distribution.

Through the coefficient of variation analysis of the four groups of data, the results are shown in Table 2.

The data discrete points in Table 2 are represented in two-dimensional coordinates, as shown in Figure 4.

As shown in Figure 4, the temperature-pressure coupling prediction model of high water-bearing gas well established in this paper has the smallest coefficient of variation in the four groups of data tests, indicating that the dispersion degree with the field measured data is the smallest and has the highest accuracy.

\section{Establishment of Downhole Throttling Model for High Water-Bearing Gas Wells}

This paper introduces the pressure and temperature changes of natural gas fluid in the gas wellbore through the choke and puts forward the solution model of downhole throttling pressure and temperature. Mainly for single-phase gas wells and high water content gas wells in downhole throttling operation, combined with downhole throttling mechanism, the downhole throttling pressure and temperature drop 
TABLE 2: Coefficient of variation of each model.

\begin{tabular}{lccc}
\hline $\begin{array}{l}\text { Coefficient of variation } \\
\text { CV }\end{array}$ & $\begin{array}{c}\text { Paper } \\
\text { model }\end{array}$ & $\begin{array}{c}\text { Hassan and } \\
\text { Kabir model }\end{array}$ & $\begin{array}{c}\text { Ramey } \\
\text { model }\end{array}$ \\
\hline $\begin{array}{l}\text { Wellbore temperature of } \\
\text { Daji 14-1 well }\end{array}$ & 0.114 & 0.162 & 0.284 \\
$\begin{array}{l}\text { Wellbore pressure of Daji } \\
\text { 14-1 well }\end{array}$ & 0.041 & 0.080 & 0.083 \\
$\begin{array}{l}\text { Wellbore temperature of } \\
\text { Daji 4-5 well }\end{array}$ & 0.169 & 0.256 & 0.293 \\
$\begin{array}{l}\text { Wellbore pressure of Daji } \\
4-5 \text { well }\end{array}$ & 0.022 & 0.037 & 0.042 \\
\hline
\end{tabular}

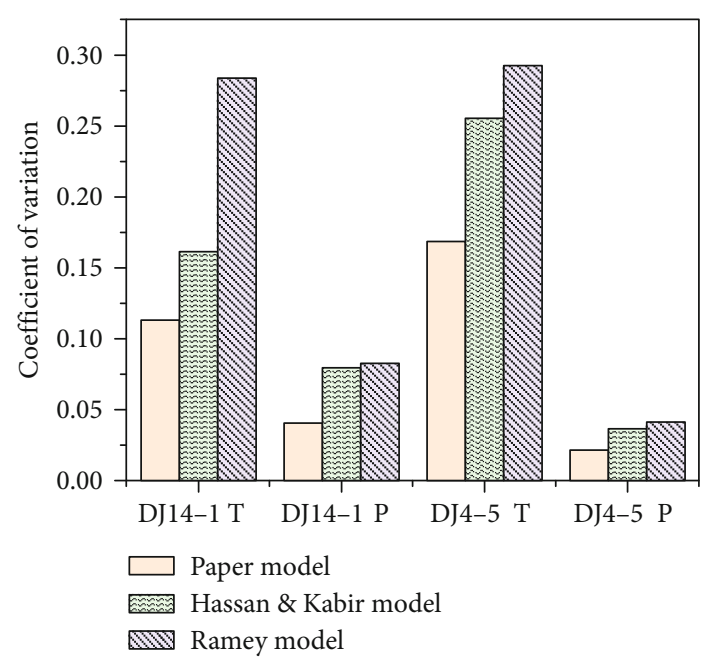

FIgURE 4: Comparison of coefficient of variation of each model.

model is established to predict the fluid flow parameters before and after throttling. Combined with the wellbore pressure and temperature prediction model, the whole wellbore pressure and temperature distribution under throttling conditions is obtained. Finally, the accuracy of the model is verified by comparing field data.

3.1. Downhole Throttling Mechanism. For conventional gas well testing, a fixed nozzle or variable nozzle is usually used for throttling and depressurization. It is of great theoretical value and practical significance to study the variation of pressure and temperature with flow and orifice diameter before and after throttling [28].

3.1.1. Thermodynamic Analysis of Downhole Throttling. The process of downhole high-pressure fluid passing through the choke belongs to isentropic expansion, accompanied by the conversion of pressure energy and kinetic energy. Natural gas does not exchange heat with the outside world during throttling, which is called adiabatic throttling [29]. Enthalpy is a function of pressure and temperature. Due to the isoenthalpy process, the pressure drop after throttling is caused by the change of temperature. Adiabatic throttling effect is usually expressed by the Joule Thomson coefficient.

$$
\alpha_{H}=\left(\frac{\partial T}{\partial p}\right)_{H} .
$$

The throttling coefficient is a physical parameter related to the specific state of gas, which can be calculated by looking up the diagram method and calculation formula. The average throttling coefficient can be calculated by means of the enthalpy pressure diagram and isoenthalpy calculation formula of natural gas, and the gas temperature after throttling can be obtained. If the temperature drop after throttling is too large and the gas temperature is too low, resulting in condensation or frost, it is advisable to reduce the gas adiabatic throttling coefficient, and measures can be taken to reduce the throttling pressure drop and increase the gas temperature before throttling.

3.1.2. Downhole Throttling Critical Flow Conditions. When natural gas flows through the choke in the well, the flow process obeys the nozzle flow equation, that is, there are critical and subcritical areas, as shown in Figure 5.

When $\left(p_{2} / p_{1}\right) \leq(2 /(k+1))^{k /(k-1)}$, the natural gas flow reaches the critical flow state, and the pressure wave generated before throttling will not be transmitted to after throttling.

When $\left(p_{2} / p_{1}\right)>(2 /(k+1))^{k /(k-1)}$, the natural gas flow is subcritical, and the pressure wave generated before throttling will be transmitted to after throttling, resulting in wellhead pressure fluctuation [30].

Therefore, the fluid is generally required to be in a critical flow state for downhole throttling design.

\subsection{Calculation of Throttling Pressure and Cooling Drop in} High Water-Bearing Gas Wells

3.2.1. Calculation of Throttling Pressure Drop in High WaterBearing Gas Wells. According to the theorem of momentum, there are

$$
G_{g 2} v_{g 2}+G_{l 2} v_{l 2}-G_{g 1} v_{g 1}-G_{l 1} v_{l 1}=\left(p_{1}-p_{2}\right) A_{2} .
$$

It is assumed that there is no mass exchange between gas and liquid phases and their respective densities do not change significantly. Continuity equations are available:

$$
\begin{gathered}
G_{g 1}=G_{g 2}=G x, \\
G_{l 1}=G_{l 2}=G(1-x), \\
v_{g 1}=\frac{G_{g 1}}{\rho_{g} A_{g 1}}=\frac{G x}{\rho_{g} A_{1} \alpha}, \\
v_{g 2}=\frac{G_{g 2}}{\rho_{g} A_{g 2}}=\frac{G x}{\rho_{g} A_{2} \alpha},
\end{gathered}
$$




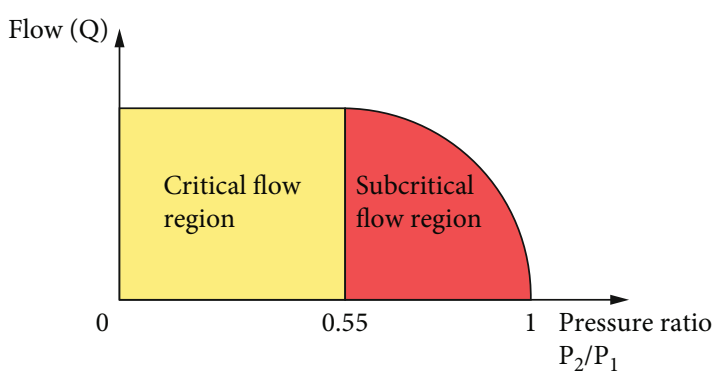

FIgURe 5: Flow characteristics of downhole choke.

$$
\begin{aligned}
& v_{l 1}=\frac{G_{l 1}}{\rho_{l} A_{l 1}}=\frac{G(1-x)}{\rho_{l} A_{1}(1-\alpha)}, \\
& v_{l 2}=\frac{G_{l 2}}{\rho_{l} A_{l 2}}=\frac{G(1-x)}{\rho_{l} A_{2}(1-\alpha)},
\end{aligned}
$$

where $\alpha_{H}$ is the change rate of temperature with pressure during natural gas throttling, if $\alpha_{H}>0$. After throttling, the temperature will be consistent with the change of pressure. $\alpha_{H}$ is not only a function of pressure but also a function of temperature. Therefore, $\Delta T$ can only be solved approximately.

Approximate calculation

$$
\Delta T=\sum_{p_{1}}^{p_{2}} \overline{\alpha_{H}} \Delta p
$$

where $\overline{\alpha_{H}}$ is the average value of $\alpha_{H}$ in the range of $\Delta p$. The calculation method is

$$
\overline{\alpha_{H}}=\sum_{p_{2}}^{p_{1}} y_{i} \alpha_{H}
$$

Substituting equations (22), (23), and (24) into equation (27) can obtain

$$
p_{2}-p_{1}=\frac{G^{2}}{A_{1}^{2} \rho_{l}} \frac{A_{1}}{A_{2}}\left(1-\frac{A_{1}}{A_{2}}\right)\left[\frac{(1-x)^{2}}{1-\alpha}+\frac{\rho_{l}}{\rho_{g}} \frac{x^{2}}{\alpha}\right] .
$$

For homogeneous flow, the section void fraction is equal to the mass void fraction, and the above formula can be simplified as

$$
\Delta p=\frac{G^{2}}{A_{1}^{2} \rho_{l}} \frac{A_{1}}{A_{2}}\left(1-\frac{A_{1}}{A_{2}}\right)\left[1+x\left(\frac{\rho_{l}}{\rho_{g}}-1\right)\right] .
$$

Obviously, through the above formula, on the premise of knowing the mass flow and fluid parameters, the gas-liquid two-phase throttling pressure drop can be calculated by formula (29).

3.2.2. Calculation of Throttling Temperature Drop in High Water-Bearing Gas Wells. In the process of gas-liquid communication through the choke, because the specific heat capacity of the liquid is much larger than that of the gas, the temperature reduction rate of the liquid is much slower than that of the gas, so the energy transfer direction is from the liquid with higher temperature to the free gas with lower temperature. In addition, because the gas-liquid two-phase flow velocity in the throat of the choke is very fast, which is generally close to or exceeds the Mach number, the heat and mass balance of the gas-liquid two-phase cannot be established again in a very short time and can only be reestablished from the throttle outlet to the pressure recovery section. The basic equation satisfied by the heat exchange capacity is

$$
Q_{\text {吸气 }}=Q_{\text {放液 }}
$$

Obviously, equation (30) expresses that the heat absorbed by the gas phase is equal to the heat released by the liquid phase when the gas and liquid are connected through the choke. Ignoring the changes of mass fraction and specific heat capacity with pressure and temperature conditions, equation (30) can be expressed as

$$
\left(1-M_{g}\right) C_{V l}\left(T_{1}-T_{2}\right)=M_{g} C_{V g}\left(T_{2}-T_{g}\right) .
$$

The left end of equation (31) fully exchanges heat to obtain heat balance due to the high temperature of the liquid phase and the heat released by the liquid; the right end represents the heat absorbed by the gas due to the low temperature of the gas phase.

Generally, the enthalpy difference is used to calculate the energy change of material in the process. The enthalpy of material is the sum of ideal gas enthalpy $H_{0}$ and isothermal enthalpy difference $\mathrm{H}-\mathrm{H}_{0}$ at this temperature. The thermodynamic equation of isothermal enthalpy difference is

$$
H-H_{0}=\int_{0}^{V}\left[T\left(\frac{\partial p}{\partial T}\right)_{V}-p\right] d V+R T(Z-1) .
$$

The equation of state of natural gas can be transformed into pressure in the form of

$$
\left(\frac{\partial p}{\partial T}\right)_{V}=\frac{R}{V-b}-\frac{\partial \alpha / \partial T}{V(V+b)+b(V-b)}
$$

Substituting (32) into (31), the isothermal enthalpy difference formula can be obtained:

$$
\begin{gathered}
\frac{H-H_{0}}{R T}=\frac{T(\partial \alpha / \partial T)-\alpha(T)}{R T 2 \sqrt{2} b} \ln \frac{Z+2.414 B}{Z-0.414 B}+(Z-1) \\
T \frac{\partial \alpha}{\partial T}=-\sum_{i=1}^{n} \sum_{j=1}^{n} x_{i} x_{j} m_{j}\left(\alpha_{i} \alpha_{j} T_{r j}\right)^{0.5}\left(1-k_{i j}\right) \\
B=\frac{b p}{R T} .
\end{gathered}
$$




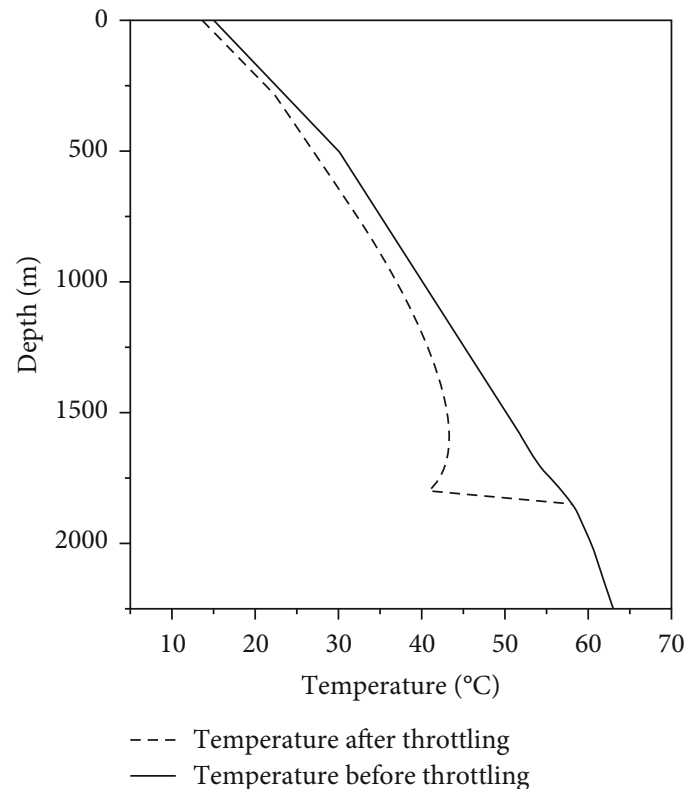

(a) Temperature comparison of Daji 4-5 well before and after throttling

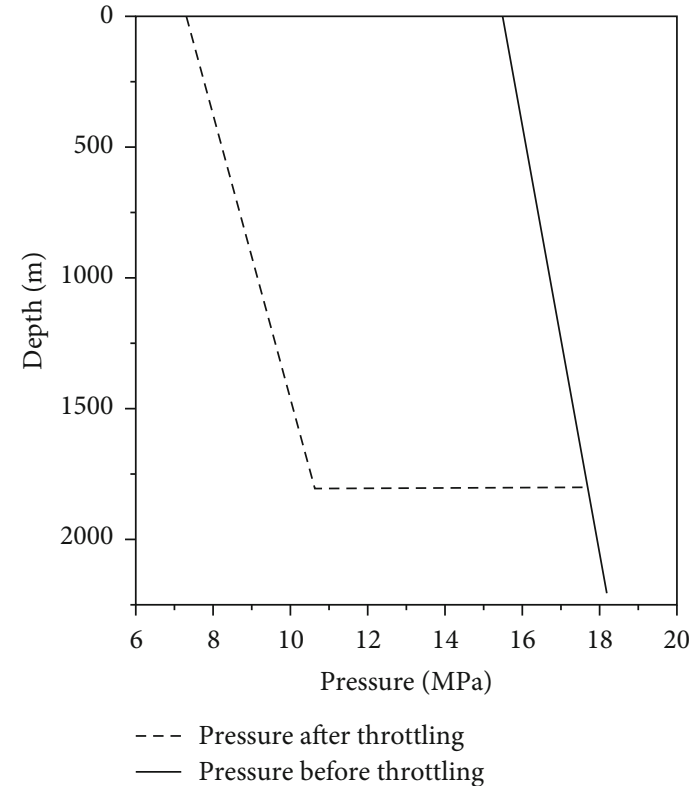

(b) Pressure comparison of Daji 4-5 well before and after throttling

FIGURE 6: Choke temperature and pressure distribution of Daji 4-5 well.

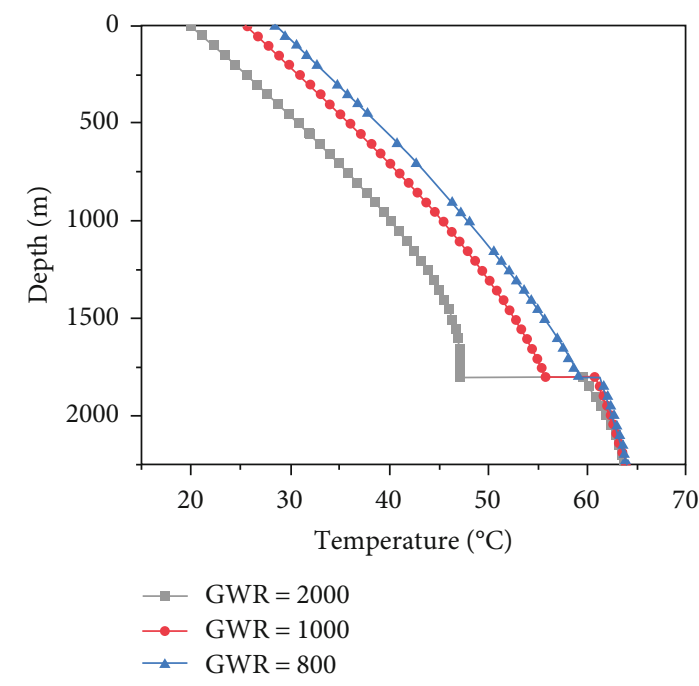

(a) Effect of gas water ratio on throttle temperature distribution

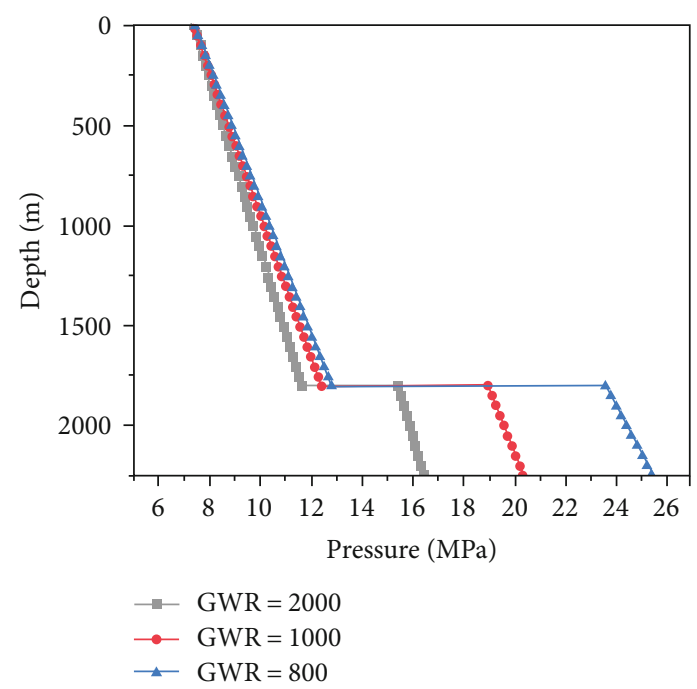

(b) Effect of gas water ratio on throttle pressure distribution

Figure 7: Effect of gas water ratio on throttle temperature and pressure distribution.

3.3. Example Analysis of Gas Well Throttling Pressure and Temperature Drop. After obtaining the throttling pressure drop and temperature drop models of single-phase gas wells and high water content gas wells, combined with the wellbore temperature and pressure model, the wellbore temperature and pressure field under throttling condition can be analyzed. Taking Daji 4-5 gas well as an example, the wellbore temperature and pressure field under throttling conditions are analyzed and its sensitivity is also analyzed. The effects of water content, choke diameter, and gas production on the temperature-pressure field under throttling conditions are mainly considered. Combined with field data, the depth of the downhole choke is verified and analyzed.
Combined with the hydrate distribution curve of well Daji $4-5, T_{h}=14.5^{\circ} \mathrm{C}$ and surface temperature $T_{d}=12.96^{\circ} \mathrm{C}$ can be obtained. Combined with the field data, the ground temperature gradient of well Daji $4-5$ is $2.4^{\circ} \mathrm{C} / 100 \mathrm{~m}$, and $M_{0}=41 \mathrm{~m} /{ }^{\circ} \mathrm{C}$ can be obtained after conversion. Take $B_{K}=$ 0.5 and $k=1.3$, and iteratively obtain $Z_{1}=0.85$ at the corresponding temperature through the deviation coefficient of wellbore natural gas. Select $4 \mathrm{~mm}$ choke diameter and substitute formula (35) as follows:

$$
L_{\min } \geq 41 \times\left[(14.5+273) \times 0.5^{-0.85 \times(1.3-1) / 1.3}-(12.96+273)\right]
$$




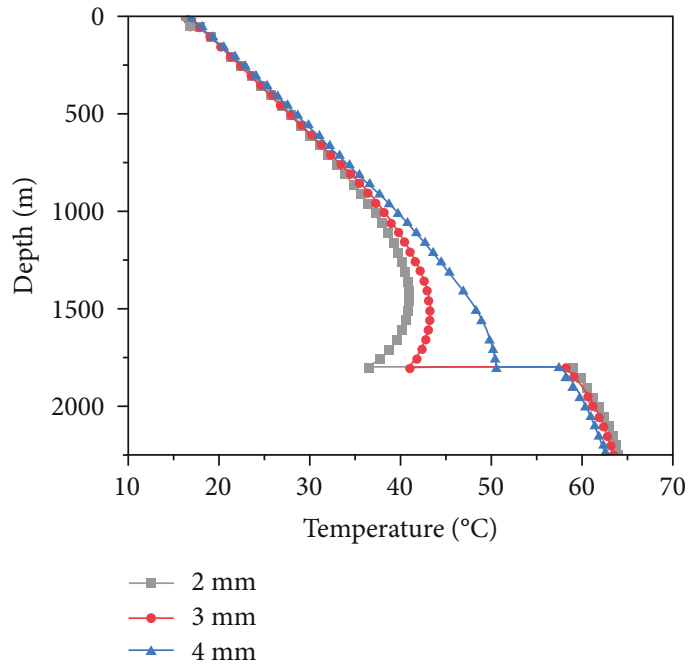

(a) Influence of choke nozzle diameter on throttle temperature distribution

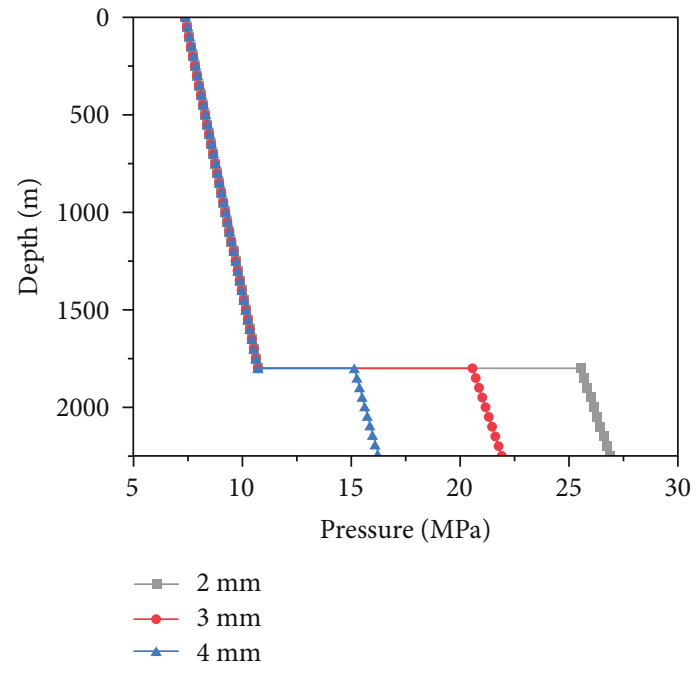

(b) Influence of choke nozzle diameter on throttle pressure distribution

FIGURE 8: Effect of throttle nozzle diameter on throttle temperature and pressure distribution.

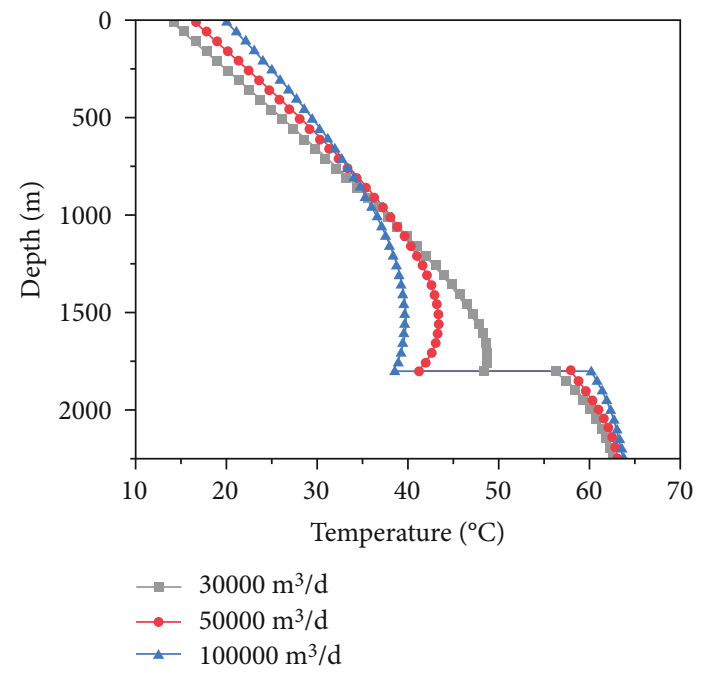

(a) Effect of gas production on throttling temperature distribution

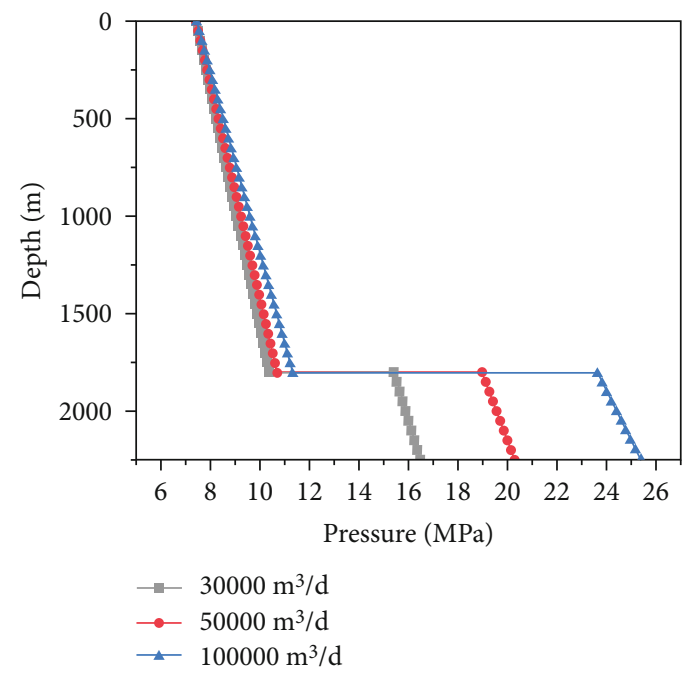

(b) Effect of gas production on throttling pressure distribution

FIGURE 9: Effect of gas production on throttling temperature and pressure distribution.

By solving equation (37), the minimum running depth of well Daji $4-5$ choke is $1800 \mathrm{~m}$. The node analysis method is used to obtain the wellbore temperature and pressure distribution under throttling conditions. The steps are as follows: (1) the temperature and pressure distribution from the bottom of the well to the inlet of the choke is solved by the wellbore temperature and pressure program. (2) The temperature and pressure distribution in the throttling section is solved by using the throttling temperature and pressure drop model. (3) Taking the throttled temperature and pressure as the new initial value and substituting it into the temperature and pressure calculation program, the temperature and pressure distribution from the choke outlet to the wellhead is solved. The calculated results are shown in Figures 2 and 3.
It can be seen from Figure 6 that the wellbore temperature and pressure distribution change strongly after throttling. When the downhole choke is lowered at the position of $1800 \mathrm{~m}$ in the wellbore, the temperature and pressure have a sudden change at this position, and the temperature and pressure have decreased significantly. Due to the heating of the fluid in the wellbore by the ground temperature gradient, the temperature of the fluid in the wellbore will recover after throttling and then gradually decrease until the wellhead. The wellhead temperature after throttling is slightly lower than that before throttling, but the overall difference is small. After throttling, the pressure decreases greatly, making the wellhead in a low-pressure state compared with that before throttling, to achieve the purpose of preventing hydrate formation. 
In the actual downhole throttling process, there are many factors affecting the wellbore temperature and pressure distribution after throttling, such as gas water ratio, choke diameter, and gas production. Through the field data, combined with the established throttling model, the sensitivity of the throttled wellbore is analyzed. The results are shown in Figures 7-9.

Combined with the throttling temperature and pressure distribution model of single-phase gas well and the throttling temperature and pressure distribution model of high water-bearing gas well, the throttling sensitivity of the Daji 4-5 gas well is analyzed. Figure 7 shows that (1) with the decrease of gas water ratio, the fluid water content in the wellbore increases and the throttling temperature decreases more; (2) on the premise of keeping the wellhead flow pressure unchanged, change the gas-water ratio to obtain the pressure change after throttling. With the decrease of gaswater ratio, the pressure before throttling becomes higher and higher, and the throttling pressure drop becomes larger and larger. Figure 8 shows that (1) with the increase of nozzle diameter, the throttling temperature drop becomes smaller and smaller. This is because the increase of nozzle diameter increases the amount of fluid passing through the nozzle at the unit interface, resulting in the weakening of the throttling effect, resulting in a smaller throttling temperature drop; (2) with the increase of orifice diameter, the throttling pressure drop decreases gradually. Figure 9 shows that (1) with the increase of gas production, the temperature before throttling gradually increases, and the throttling temperature drops gradually increases. The higher the production, the higher the wellhead temperature after throttling. (2) With the increase of gas production, the pressure before throttling increases gradually, and the pressure drop increases gradually.

3.4. Numerical Simulation of Downhole Throttling. In order to obtain the variation of internal parameters of the throttling flow field, CFD simulation can be used. The gas-water mixing choke can be regarded as a steady and compressible flow problem of fluid through sudden contraction and sudden expansion pipeline. The purpose of the solution is to simulate the velocity field and temperature field of the downhole choke through Fluent. The working medium is gas-water two-phase fluid. Usually, the fluid flow state will change after passing through this pipeline. With reference to the actual parameters of the well example, the outer diameter is selected as $\Phi 73 \mathrm{~mm}$ tubing movable downhole choke with an inner diameter of $\Phi 62 \mathrm{~mm}$, choke diameter $d=3.8$ $\mathrm{m}$, length $l=20 \mathrm{~mm}$, inlet section $L_{1}=100 \mathrm{~mm}$, and outlet section $L_{2}=300 \mathrm{~mm}$. The structural model is shown in Figure 10.

The structural grid in this paper is mainly generated by ICEM CFD 2020 R2, and the boundary layer at the throttle valve is encrypted. At the same time, in order to reduce the number of grids, a coarser grid is used in the part where the inlet and outlet are far away from the throttle valve. The grid diagram is shown in Figure 11. Through the grid independence analysis, the number of grids greater than 200,000 has no effect on the calculation results. Finally, about

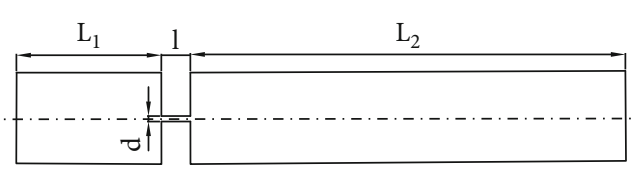

FIgURe 10: Geometric model of restrictor.

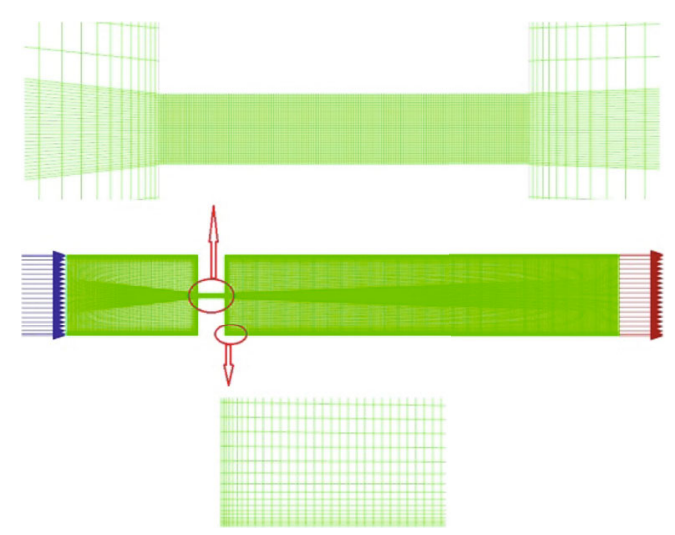

FIgURE 11: Schematic diagram of mesh.

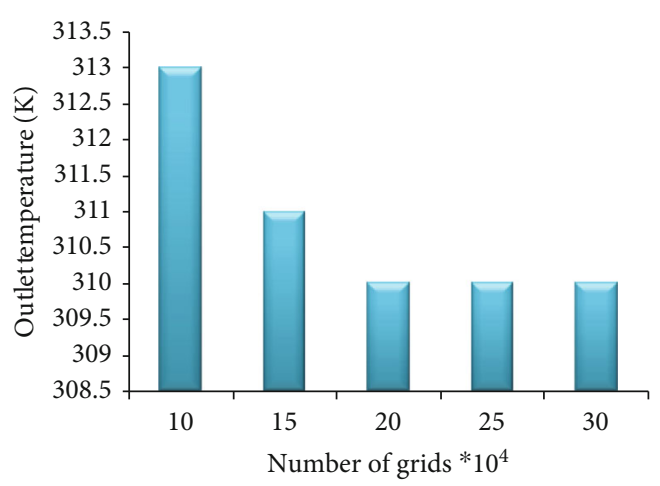

Figure 12: Mesh independence.

200,000 grids are selected for calculation, as shown in Figure 12.

We use Fluent to run the model. First, open multiphase model, energy model, and viscous model, respectively. Then, in the multiphase flow model, phase 1 is defined as the main phase as methane, and phase 2 is defined as the dispersed phase as water-liquid. Throttle inlet pressure $p_{1}=17.5 \mathrm{MPa}$ , $T_{1}=340 \mathrm{~K}$. Throttle outlet pressure $p_{2}=6 \mathrm{MPa}, T_{2}=300$ $\mathrm{K}$. The flow of natural gas in the restrictor is considered as a steady state.

Using energy equation and standard $k$-omega model, the natural gas flow in the restrictor is regarded as a compressible fluid. The mixture homogenization model based on pressure is used to simulate the changes of pressure, velocity, and temperature in the internal flow field of the restrictor.

The general change trend of pressure is that the gas pressure before throttling does not change significantly. The cross-sectional area at the throttling inlet decreases sharply and the flow rate increases abruptly (as shown in Figure 13), resulting in the instantaneous reduction of the 


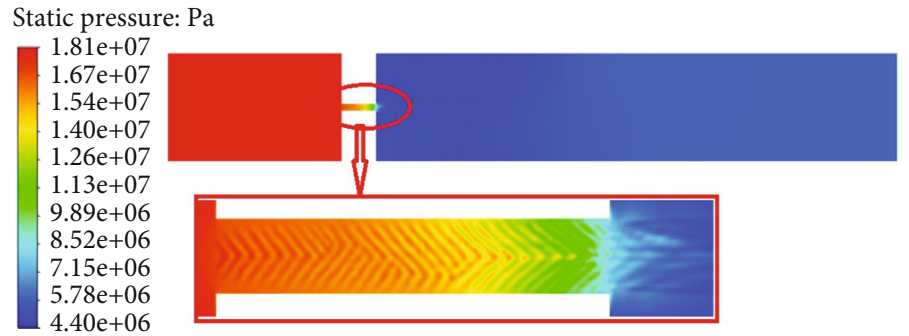

Figure 13: Pressure nephogram and curve of flow field in restrictor.

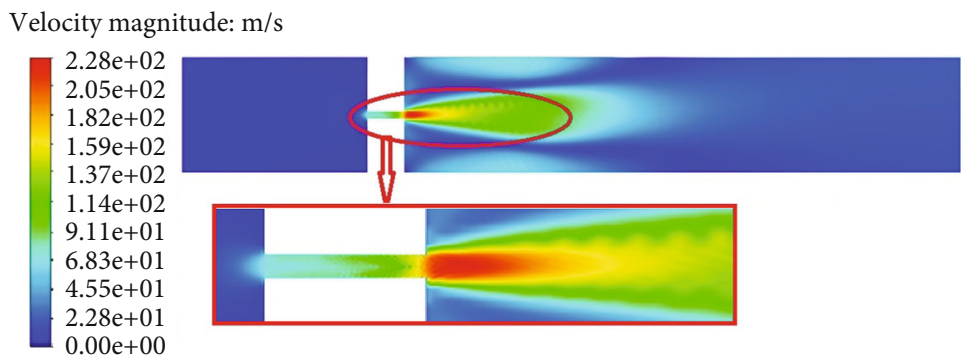

FIGURE 14: Cloud diagram and curve of flow field velocity in restrictor.

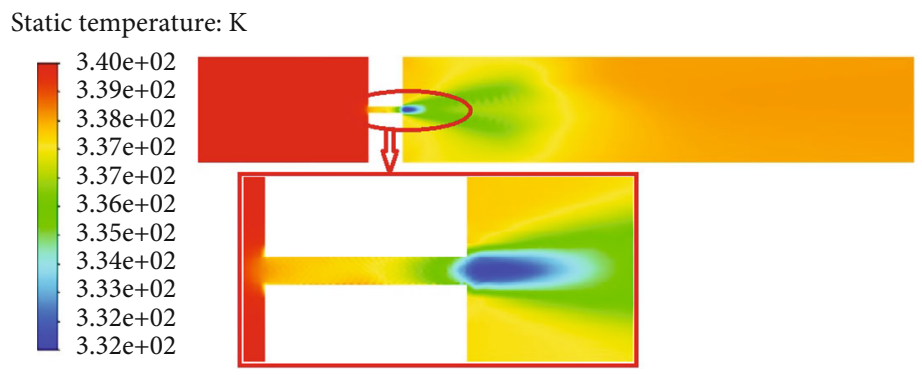

FIgURE 15: Cloud diagram and curve of total temperature of flow field in restrictor.

internal flow field from high pressure to low pressure (as shown in Figure 14). Throttling converts the pressure energy into kinetic energy. Near the throttling outlet, the flow rate of high-speed gas begins to decrease with the mixing with the surrounding gas. The pressure rises to a certain extent and then tends to be stable. It can be seen from the temperature distribution curve in Figure 15 that there is a large temperature drop process at the throttling position. The temperature of the fluid reaches the lowest value after passing through the throttling nozzle, and then, the lowtemperature gas and the surrounding gas fuse and rise gradually under the action of the ground temperature gradient.

\section{Summary and Conclusions}

Compared with the Ramey model and Hassan and Kabir model, the wellbore temperature and pressure coupling prediction model of the high water content gas well in this paper is closer to the field measured data.

(1) With the decrease of gas water ratio, the fluid water content in the wellbore increases and the throttling temperature decreases more
(2) On the premise of keeping the wellhead flow pressure unchanged, change the gas-water ratio to obtain the pressure change after throttling. With the decrease of gas-water ratio, the pressure before throttling becomes higher and higher, and the throttling pressure drop becomes larger and larger. With the increase of the orifice diameter, the throttling temperature drop becomes smaller and smaller. This is because the increase of the orifice diameter increases the amount of fluid passing through the orifice at the unit interface, resulting in the weakening of the throttling effect, resulting in the smaller throttling temperature drop

(3) With the increase of orifice diameter, the throttling pressure drop decreases gradually. With the increase of gas production, the temperature before throttling increases gradually, and the throttling temperature drop increases gradually. The higher the production, the higher the wellhead temperature after throttling

(4) With the increase of gas production, the pressure before throttling increases gradually, and the pressure drop increases gradually. There is a large 
temperature drop process at the throttling position. When the fluid passes through the throttling nozzle, the temperature reaches the lowest value, and then, the low-temperature gas merges with the surrounding gas and rises gradually under the action of the ground temperature gradient

In conclusion, through comparison, the model established in this paper has more accurate prediction data, but this research model is only applicable to the prediction and calculation of temperature and pressure field of high water cut two-phase flow gas wells.

\section{Nomenclature}

$\rho_{g}$ and $\rho_{l}$ : Gas density and liquid density $\left(\mathrm{kg} / \mathrm{m}^{3}\right)$

$u_{g}$ and $u_{l}$ : Gas flow rate and liquid flow rate $(\mathrm{m} / \mathrm{s})$

$a: \quad$ Section air content

Q: $\quad$ Mass flow $(\mathrm{kg} / \mathrm{s})$

$G$ : $\quad$ Mass flow rate $\left(\mathrm{kg} /\left(\mathrm{m}^{2} \cdot \mathrm{s}\right)\right)$

$\beta: \quad$ Volumetric gas content

$\tau$ : $\quad$ Shear stress between fluid and pipe wall $\left(\mathrm{N} / \mathrm{m}^{2}\right)$, $\tau=(A / \pi d) \rho_{m} g \cdot 4 f(1 / d)\left(v^{2} / 2 g\right)$

$f$ : The frictional resistance coefficient of two-phase flow

G: $\quad$ Mass flow rate $\left(\mathrm{kg} /\left(\mathrm{m}^{2} \cdot \mathrm{s}\right)\right)$

$v_{m}: \quad$ The specific volume of two-phase flow $\left(\mathrm{kg} / \mathrm{m}^{3}\right)$

$h: \quad$ Specific enthalpy $(\mathrm{J} / \mathrm{kg})$

$V_{m}: \quad$ Flow rate of mixture $(\mathrm{m} / \mathrm{s})$

q: $\quad$ Heat of unit control body $(\mathrm{J} / \mathrm{m} \cdot \mathrm{s})$

Q: $\quad$ Mass flow of wellbore fluid $(\mathrm{kg} / \mathrm{s})$

$C_{p}$ : $\quad$ Specific heat capacity of fluid at constant pressure $(\mathrm{J} /(\mathrm{kg} \cdot \mathrm{K}))$

$C_{J}: \quad$ Joule Thomson coefficient of gas-liquid twophase fluid

$r_{\text {to }}: \quad$ Outer diameter of oil pipe $(\mathrm{m})$

$U_{\text {to }}$ : Total heat transfer coefficient $(\mathrm{J} /(\mathrm{m} \cdot \mathrm{s} \cdot \mathrm{K}))$

$T_{f}: \quad$ Wellbore fluid temperature (K)

$T_{s}: \quad$ Temperature of the second contact surface $(\mathrm{K})$

$k_{e}: \quad \quad$ Formation thermal conductivity $(\mathrm{J} /(\mathrm{m} \cdot \mathrm{s} \cdot \mathrm{K}))$

$T_{\mathrm{ei}}: \quad$ Formation temperature at any depth $(\mathrm{K})$

$f(t)$ : Dimensionless time function

$T_{\text {fout }}$ : $\quad$ Fluid temperature at the outlet of each section (K)

$z_{\text {out }}: \quad$ Outlet of each section (m)

$z_{\text {in }}$ : $\quad$ Entrance of each section $(\mathrm{m})$

$T_{\text {fin }}$ : $\quad$ Fluid temperature at the inlet of each section (K)

$T_{\text {eout }}: \quad$ Formation temperature at the outlet of each section $(\mathrm{K})$

$T_{\text {ein }}$ : $\quad$ Formation temperature at the inlet of each section $(\mathrm{K})$

$w: \quad$ Mass flow of wellbore fluid $(\mathrm{kg} / \mathrm{s})$

$W_{g}: \quad$ Gas mass flow $(\mathrm{kg} / \mathrm{s})$

$Z_{g}: \quad$ Deviation coefficient of natural gas

$\rho_{g}: \quad$ Gas density $\left(\mathrm{kg} / \mathrm{m}^{3}\right)$

$\rho_{l}: \quad$ Liquid density $\left(\mathrm{kg} / \mathrm{m}^{3}\right)$

$C_{v}: \quad$ Coefficient of variation

$\sigma: \quad$ Standard deviation

$\begin{array}{ll}\mu: & \text { Average value } \\ G: & \text { Mass flow }(\mathrm{kg} / \mathrm{s}) \\ v: & \text { Flow rate }(\mathrm{m} / \mathrm{s}) \\ A_{2}: & \text { Throat sectional area }\left(\mathrm{m}^{2}\right) ; g \text { and } l \text {, respectively, } \\ & \text { represent gas phase and liquid phase, and } 1 \text { and } \\ & 2 \text { represent throttle inlet and throttle throat, } \\ & \text { respectively } \\ x: & \text { Mass air content } \\ \alpha: & \text { Section void content } \\ y_{i}: & \text { Mole fraction of component } i \text { in the gas phase } \\ \Delta T: & \text { Temperature change before and after throttling } \\ & \text { (K) } \\ \Delta_{p}: & \text { Pressure change before and after throttling } \\ & \text { (MPa) } \\ p_{1} \text { and } p_{2}: & \text { Pressure value before and after throttling }(\mathrm{MPa}) \\ M_{g}: & \text { Gas phase mass fraction } \\ C_{V l}: & \text { Specific heat capacity of liquid phase at constant } \\ C_{V g}: & \text { volume }(\mathrm{kJ} /(\mathrm{kg} \cdot \mathrm{K})) \\ & \text { Specific heat capacity of gas phase at constant } \\ T_{2}: & \text { volume }(\mathrm{kJ} /(\mathrm{kg} \cdot \mathrm{K})) \\ T_{2}: & \text { Temperature before throttling }(\mathrm{K}) \\ T_{g}: & \text { Gas-liquid two-phase heat balance temperature } \\ k_{i j}: & \text { after throttling }(\mathrm{K}) \\ T_{r j}: & \text { Temperature under downstream pressure of } \\ \mathrm{R}: & \text { isoenthalpy process }(\mathrm{K}) \\ & \text { Adiabatic index of natural gas with different } \\ & \text { Components } \\ & \text { Gas constant }(8314 \mathrm{~kJ} /(\mathrm{kmol} \cdot \mathrm{K})) . \\ & \end{array}$

Data Availability

The manuscript is a data self-contained article, whose results were obtained from the laboratory analysis, and the entire data are presented within the article.

\section{Conflicts of Interest}

The authors declare that there is no conflict of interest regarding the publication of this paper.

\section{Acknowledgments}

This project was supported by the National Natural Science Foundation of China (52004215, 12101482, and 51674199) and Graduate Innovation and Practical Ability Training Program of Xi'an Shiyou University (YCS211053).

\section{References}

[1] B. Moradi, M. Ayoub, M. Bataee, and E. Mohammadian, "Calculation of temperature profile in injection wells," Journal of Petroleum Exploration and Production Technology, vol. 10, no. 2, pp. 687-697, 2020.

[2] X. Li, J. Zhang, X. Tang, G. Mao, and P. Wang, "Study on wellbore temperature of riserless mud recovery system by CFD approach and numerical calculation," Petroleum, vol. 6, no. 2 , pp. 163-169, 2020. 
[3] H. Jung, D. N. Espinoza, and S. A. Hosseini, "Wellbore injectivity response to step-rate $\mathrm{CO}_{2}$ injection: coupled thermoporo-elastic analysis in a vertically heterogeneous formation," International Journal of Greenhouse Gas Control, vol. 102, article 103156, 2020.

[4] Z. Guo, H. Wang, and M. Jiang, "A simple analytical model of wellbore stability considering methane hydrate saturationdependent elastoplastic mechanical properties," Journal of Petroleum Science and Engineering, vol. 207, article 109104, 2021.

[5] Y. Li, Y. Cheng, C. Yan et al., "Mechanical study on the wellbore stability of horizontal wells in natural gas hydrate reservoirs [J]," Journal of Petroleum Science and Engineering, vol. 207, article 109104, 2021.

[6] Z. Wang, M. Yang, and Y. Chen, "Numerical modeling and analysis of induced thermal stress for a non-isothermal wellbore strengthening process," Journal of Petroleum Science and Engineering, vol. 175, pp. 173-183, 2019.

[7] W. Sifan, Z. Ankang, and H. Dongfeng, "Research and Field Tests of Coiled Tubing Fishing Technology for Sand-Buried Throttles [J]," Petroleum Drilling Techniques, vol. 49, no. 5, pp. 108-113, 2021.

[8] H. N. Wang, X. P. Chen, M. J. Jiang, and Z. Y. Guo, “Analytical investigation of wellbore stability during drilling in marine methane hydrate-bearing sediments," Journal of Natural Gas Science and Engineering, vol. 68, article 102885, 2019.

[9] L. Zhang, S. Qu, C. Wang, and B. Guan, "Prediction temperature field and wax deposition based on heat-fluid coupling method," Journal of Petroleum Exploration and Production Technology, vol. 9, no. 1, pp. 639-644, 2019.

[10] M. Mansourpoor, R. Azin, S. Osfouri, and A. A. Izadpanah, "Study of wax disappearance temperature using multi-solid thermodynamic model," Journal of Petroleum Exploration and Production Technology, vol. 9, no. 1, pp. 437-448, 2019.

[11] J. Yang, Y. Feng, B. Zhang, Y. Tang, and Z. Jiang, "A blockage removal technology for natural gas hydrates in the wellbore of an ultra-high pressure sour gas well," Natural Gas Industry B, vol. 8, no. 2, pp. 188-194, 2021.

[12] H. Wang, "A non-isothermal wellbore model for high pressure high temperature natural gas reservoirs and its application in mitigating wax deposition," Journal of Natural Gas Science and Engineering, vol. 72, article 103016, 2019.

[13] Y. Gholamzadeh, M. Sharifi, A. Karkevandi-Talkhooncheh, and M. K. Moraveji, "A new physical modeling for twophase wellbore storage due to phase redistribution," Journal of Petroleum Science and Engineering, vol. 195, article 107706, 2020.

[14] N. Wei, J. Zhao, W. Sun et al., "Non-equilibrium multiphase wellbore flow characteristics in solid fluidization exploitation of marine gas hydrate reservoirs," Natural Gas Industry B, vol. 6, no. 3, pp. 282-292, 2019.

[15] M. M. Abdelhafiz, L. A. Hegele, and J. F. Oppelt, "Temperature modeling for wellbore circulation and shut-in with application in vertical geothermal wells," Journal of Petroleum Science and Engineering, vol. 204, article 108660, 2021.

[16] R. G. Turner, M. G. Hubbard, and A. E. Dukler, "Analysis and prediction of minimum flow rate for the continuous removal of liquids from gas wells," Journal of Petroleum Technology, vol. 21, no. 11, pp. 1475-1482, 1969.
[17] H. E. Gray, Vertical Flow Correlation in Gas Wells [J]. User Manual for API14B, Subsurface Controlled Safety Valve Sizing Computer Program, 1974.

[18] B. Guo, A. Ghalambor, and C. Xu, "A systematic approach to predicting liquid loading in gas wells," SPE Production \& Operations, vol. 21, no. 1, pp. 81-88, 2006.

[19] M. Li, S. L. Li, and L. T. Sun, "New view on continuousremoval liquids from gas wells," SPE Production \& Facilities, vol. 17, no. 1, pp. 42-46, 2002.

[20] P. Chaoyang, "Study on critical liquid carrying flow of gas wells [J]," Journal of Petroleum, vol. 12, no. 1, pp. 72-74, 2010.

[21] W. Zhibin and L. Yingchuan, "Continuous liquid carrying mechanism of gas wells [J]," Journal of Petroleum, vol. 33, no. 4, pp. 681-686, 2012.

[22] Y. Zhi, M. Jixiang, and H. Pan, "Study on downhole throttling and its influence on liquid carrying capacity [J]," Inner Mongolia petrochemical industry, vol. 12, no. 7, pp. 6-9, 2012.

[23] L. Gang, "A new method for critical flow of liquid carrying in gas wells [J]," Fault block oil and gas reservoir, vol. 21, no. 3, pp. 339-343, 2014.

[24] Z. Yang, "Analysis of wellbore effusion in low production and low pressure gas wells [J]," Neijiang science and technology, vol. 39, no. 5, pp. 74-75, 2018.

[25] D. Jinbao, Study on Gas-Liquid Two-Phase Flow Characteristics and Critical Liquid Carrying Model in Gas Well Bore [D], Xi'an University of petroleum, 2020.

[26] M. Wei and L. Zheng, "Coupling analysis of gas well wellbore pressure and temperature [J]," Natural Gas Industry, vol. 19, no. 6, pp. 66-68, 1999.

[27] H. Ramey Jr., "Wellbore heat transmission," Journal of Petroleum Technology, vol. 14, no. 4, pp. 427-435, 1962.

[28] Y. Yu, W. Wang, Y. Peng, H. Tan, Z. Dong, and W. Zhou, "Application and design method of downhole throttling technology for ultra-high pressure gas wells [J]," Natural gas and oil, vol. 38, no. 6, pp. 80-85, 2020.

[29] Z. Youwei, S. Haiguang, Z. Yuhao, J. Zhichen, S. Yufa, and G. Yonghai, Hydrate prevention analysis of downhole throttling technology for deep-water high-pressure gas wells [C] / / Proceedings of the 31st national hydrodynamic Symposium (Volume II), pp. 253-260, 2020.

[30] Q. Caiting, Analysis of Downhole Choke Point System of Water Producing Gas Well [D], Northeast Petroleum University, 2018. 